\title{
MicroRNAs recruit elF4E2 to repress translation of target mRNAs
}

\author{
Shaohong Chen ${ }^{1,2}$, Guangxia Gao ${ }^{1,2}$ \\ ${ }^{1}$ CAS Key Laboratory of Infection and Immunity, CAS Center for Excellence in Biomacromolecules, Institute of Biophysics, \\ Chinese Academy of Sciences, Beijing 100101, China \\ 2 University of Chinese Academy of Sciences, Beijing 100101, China \\ $\bowtie$ Correspondence: gaogx@moon.ibp.ac.cn (G. Gao) \\ Received June 26, 2017 Accepted July 6, 2017
}

\begin{abstract}
MicroRNAs (miRNAs) recruit the RNA-induced silencing complex (RISC) to repress the translation of target mRNAs. While the 5' 7-methylguanosine cap of target mRNAs has been well known to be important for miRNA repression, the underlying mechanism is not clear. Here we show that TNRC6A interacts with elF4E2, a homologue of elF4E that can bind to the cap but cannot interact with eIF4G to initiate translation, to inhibit the translation of target mRNAs. Downregulation of elF4E2 relieved miRNA repression of reporter expression. Moreover, elF4E2 downregulation increased the protein levels of endogenous IMP1, PTEN and PDCD4, whose expression are repressed by endogenous miRNAs. We further provide evidence showing that miRNA enhances elF4E2 association with the target mRNA. We propose that miRNAs recruit elF4E2 to compete with elF4E to repress mRNA translation.
\end{abstract}

KEYWORDS microRNAs, translation repression, 5' cap, elF4E2, TNRC6A

\section{INTRODUCTION}

MicroRNAs (miRNAs) are 21-23 nucleotides noncoding RNAs that regulate the expression of messenger RNAs. miRNA-mediated gene silencing plays important roles in a variety of biological processes (Flynt and Lai, 2008; Jonas and Izaurralde, 2015). miRNAs in complex with Argonaute proteins (Ago1-4) bind to target mRNAs through nucleotide

Electronic supplementary material The online version of this article (doi:10.1007/s13238-017-0444-0) contains supplementary material, which is available to authorized users. pairing and recruit one of the TNRC6 proteins (TNRC6A-6C) to form the RNA-induced silencing complex (RISC) (Pfaff and Meister, 2013). RISC can promote target mRNA translation repression, degradation or both (Fabian et al., 2010).

There is increasing evidence indicating that translation initiation is a major target of miRNA repression (Pillai et al., 2005; Meister, 2007; Mathonnet et al., 2007; Fukaya et al., 2014; Humphreys et al., 2005; Thermann and Hentze, 2007; Fukaya and Tomari, 2012; Wang et al., 2008; Ricci et al., 2013; Gu et al., 2014). Cellular mRNAs have a 7-methylguanosine (m7GpppN) cap structure at the $5^{\prime}$ end, which promotes translation and mRNA stability (Varani, 1997). The cap is recognized by the translation initiation factor elF4E, which recruits other translation initiation factors, including elF4G, the RNA helicase elF4A, elF2, elF3 and the $40 \mathrm{~S}$ small ribosomal subunit to initiate translation (Gingras et al., 1999). elF4A and its homologue elF4A2 are important for unwinding structures in the $5^{\prime}$ untranslated regions (5'UTRs) (Lu, et al., 2014). It was reported that RISC-induced dissociation of elF4A or elF4A2 caused miRNA repression (Lu et al., 2014; Meijer et al., 2013; Fukao et al., 2014). These results partially explain how miRNAs repress translation initiation.

It has been well documented that the $5^{\prime}$ cap is important for miRNA repression. In contrast to the cap-containing mRNA reporters, internal ribosome entry site (IRES)-initiated mRNA reporters are refractory to miRNA silencing (Pillai et al., 2005; Mathonnet et al., 2007; Humphreys et al., 2005; Walters et al., 2010). IRES can bypass the cap to recruit ribosomes to the mRNA internally to initiate translation (Jackson et al., 2010). Addition of a cap to the IRES mRNA reporters conferred sensitivity to miRNA silencing (Walters et al., 2010). On the other hand, some other work showed that IRES-dependent translation can also be repressed by miRNA (Humphreys et al., 2005; Petersen et al., 2006). As is 
a proper explanation in Valencia-Sanchez et al.'s 2006 review, miRNAs also work through other elements to repress target mRNA, such as poly $(A)$ tail and $5^{\prime}$ cap structure and these miRNA-repression related elements might be missing in some reporters.

That cap optimizes miRNA silencing strongly suggests that a cap-binding protein should be involved in miRNA repression (Kiriakidou et al., 2007). It was reported that human Ago2 bound to the cap through two conserved phenylalanine residues (F450 and F505) and thereby prevented the recruitment of elF4E in miRNA repression (Kiriakidou et al., 2007). However, this conclusion was challenged by later studies. Those two residues were shown to be important for Ago interaction with GW182 rather than binding to the cap in both human and flies (Eulalio et al., 2008). Further structure analysis showed that in human Ago2 one of the aromatic side chains F450 is buried in the hydrophobic core (Kinch and Grishin, 2009) and MID domain of human Ago2 cannot bind cap analogues significantly (Frank et al., 2011), although Drosophila Ago1 and Neurospora Argonaute contains a 5' cap binding site (Boland et al., 2010; Djuranovic et al., 2010). Moreover, fly Ago-RISC associated with target mRNA in a manner independent of GW182 and repressed translation without affecting elF4E recognition of the cap (Fukaya et al., 2014), further arguing against the idea that Ago binding to the cap is required for translation repression.

elF4E2 is a homologue of elF4E (Rom et al., 1998). The binding affinity of elF4E2 for the cap is about 100-fold lower than elF4E, and the abundance in cells is about 10-fold lower (Zuberek et al., 2007). In addition, unlike elF4E, elF4E2 does not interact with elF4G to initiate translation (Rom et al., 1998). When recruited to the cap of an mRNA by transacting factors, elF4E2 can repress the translation of the target mRNA. For example, Drosophila Bicoid recruits elF4E2 to suppress caudal translation (Cho et al., 2005), and
TTP recruits elF4E2 to repress the translation of AU-rich element-containing mRNAs (Tao and Gao, 2015; Fu et al., 2016).

elF4E2 was reported to interact with 4E-T (Kubacka et al., 2013), which participates in translation repression and mRNA decay in TTP or microRNA mediated silencing (Kamenska et al., 2014; Kamenska et al., 2016; Nishimura et al., 2015). A very recent research shows that elF4E2 effects miRNA mediated translation silencing by competing with elF4E for binding 4E-T (Chapat, 2017). In the present study, we confirmed that elF4E2 is required for miRNA mediated translation repression. In addition, we provide evidence indicating that TNRC6A, the core component of RISC, can directly recruit elF4E2 to target mRNA to repress translation.

\section{RESULTS}

The $5^{\prime}$ cap of target mRNA is required for optimal miRNA-mediated gene silencing

To determine the contributions of the cap and structured $5^{\prime}$ UTR to miRNA silencing, reporter mRNAs expressing firefly luciferase (fLuc) were generated by in vitro transcription (Fig. 1A). In the $3^{\prime} U T R$ of these reporters, there were eight tandem Let7a-responsive elements (LREs), which are responsive to endogenous let-7a in HeLa cells. Reporters containing mutant responsive elements (REm) were constructed to serve as negative controls (Fig. 1A). In the $5^{\prime} U T R$ there was a stem-loop (SL), which mimics a secondary structure, or repetitive CAA sequences, which cannot form secondary structures. The translation of the reporters was driven either by the cap or by EMCV IRES. EMCV IRESdriven translation does not need elF4E but requires the rest translation initiation factors (Jackson et al., 2010). A reporter expressing renilla luciferase $(R L)$ driven by EMCV IRES was used to serve as a control for transfection efficiency and
A

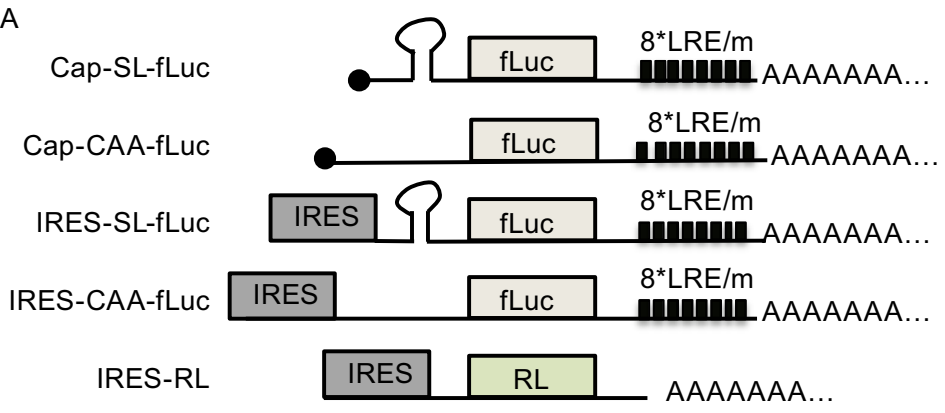

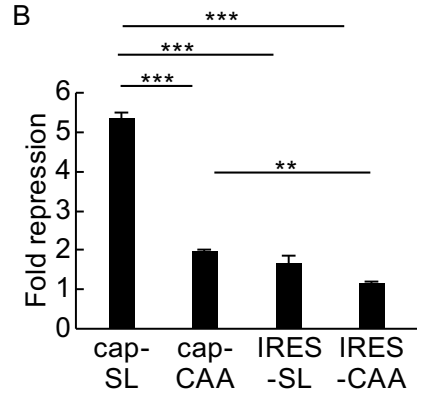

Figure 1. The cap structure of target mRNA is required for optimal miRNA-mediated gene silencing. (A) Schematic representation of the reporter mRNAs. Eight tandem Let-7a response elements (LRE) or mutants (REm) were cloned downstream of the coding sequence of firefly luciferase (fLuc). A stem-loop (SL) structured fragment or a fragment containing (CAA) ${ }_{18}$ was inserted into the 5'UTR of the reporters indicated. (B) Reporter mRNAs were transfected into HeLa cells. A control reporter expressing renilla luciferase (RL) driven by EMCV IRES was included. At $24 \mathrm{~h}$ postinfection, luciferase activities were measured and firefly luciferase activity was normalized with renilla luciferase activity. Data presented are means $\pm \mathrm{SD}$ of three independent experiments. The $P$ value is determined by two-tailed Student's $t$ test. ns, nonsignificant. ${ }^{\star \star} P<0.01$; ${ }^{* \star \star} P<0.005$. 
sample handling (Fig. 1A). The reporters were transfected into HeLa cells and luciferase activities were measured. The response of a reporter to let-7a silencing was indicated by fold repression, which was calculated as the luciferase activity expressed from the REm reporter divided by that expressed from the LRE reporter. That equivalent amounts of the mRNA reporters were transfected into the cells was confirmed by RT-qPCR (Fig. S1). Data showed that let-7a repressed the expression of the reporter containing both the cap and the stem-loop (Cap-SL-fLuc) by about 5-fold (Fig. 1B). The reporter containing the stem-loop and not the cap (IRES-SL-fLuc) was repressed by about 2-fold (Fig. 1B). The reporter containing the cap but not the stemloop (Cap-CAA-fLuc) was still responsive, with the repression about 2-fold (Fig. 1B). When both the cap and the stem-loop were removed, the reporter (IRES-CAA-fLuc) was barely responsive (Fig. 1B). These results confirmed that both the cap and a structured 5'UTR contribute to miRNA repression.

\section{TNRC6A interacts with elF4E2}

We next explored the interactions between RISC and capbinding proteins elF4E (referred to as elF4E1 hereafter) and its homologue elF4E2. TNRC6 proteins, key players in miRNA repression, were tested for their interactions with elF4E1 and elF4E2 by coimmunoprecipitation assays. Data showed that immunoprecipitation of both TNRC6A and $6 \mathrm{~B}$ coprecipitated elF4E2 (Fig. 2A). In contrast, immunoprecipitation of TNRC6A or TNRC6B failed to coprecipitate elF4E1 (Fig. 2A). The interaction between TNRC6A/6B and 4E2 is consistent with the BiolD results in the recent paper by Chapat et al. (2017). We tried to detect the interaction between endogenous TNRC6A and elF4E2 but failed (data not shown). This could be accounted for by technical difficulties such as low abundance of the endogenous elF4E2, degradation of TNRC6A, and lack of good antibodies. We then analyzed the interaction between endogenous TNRC6A and overexpressed elF4E2. Data showed that immunoprecipitation of endogenous TNRC6A coprecipitated Flag-tagged elF4E2 but not elF4E1 (Fig. 2B).

To map the domain(s) of TNRC6A that is involved in its interaction with elF4E2, TNRC6A truncation mutants were constructed and tested for their interactions with Flag-tagged elF4E2 (Fig. 2C). Data showed that the C-terminal domain of TNRC6A (TNRC6A-C) displayed considerable interaction with eIF4E2 while the other domains failed to do so although the middle domain (TNRC6A-M) had some weak interaction (Fig. 2C). Further truncations of TNRC6A-C abolished its interaction with elF4E2 (Fig. 2C). To test whether the interaction between TNRC6A-C and elF4E2 is direct, they were bacterially expressed, partially purified and analyzed by the pull-down assays. Indeed, the recombinant GST-tagged TNRC6A-C pulled down elF4E2 but not elF4E1 (Fig. 2D). These results indicate that elF4E2 directly interacts with the C-terminal domain of TNRC6A.

\section{Downregulation of elF4E2 impairs miRNA silencing}

To explore the role of elF4E2 in miRNA-mediated translational repression, we analyzed the effects of elF4E2 downregulation on miRNA silencing of two reporters, the Let7aresponsive LRE reporter and the miR-19-responsive 19RE reporter (Fig. 3A). Two shRNAs targeting different sites of elF4E2 were constructed and confirmed for their ability to downregulate the expression of endogenous elF4E2 (Fig. 3B). In the absence of the shRNA targeting elF4E2, ectopic expression of let-7a inhibited the LRE reporter expression by about 8-fold (Fig. 3C). In comparison, downregulation of elF4E2 significantly reduced the repression (Fig. 3C). The relatively high expression level of miR-19 in HEK293 cells allowed us to use the endogenous miR-19 to inhibit 19RE reporter expression. A reporter containing REm (Fig. 3A) was used as a negative control. MiR-19 repression of the 19RE reporter expression was defined as the luciferase activity expressed from the REm reporter divided by that expressed from the 19RE reporter. In the absence of the shRNA targeting elF4E2, the repression was about 12-fold (Fig. 3D). In comparison, downregulation of elF4E2 reduced the repression to about 6-fold (Fig. 3D). These results indicate that downregulation of elF4E2 impaired miRNA repression of reporter expression.

\section{Downregulation of elF4E2 relieves miRNA repression of target mRNA translation}

We next used the polysome profiling assay to confirm that elF4E2 participates in miRNA mediated translational repression. Overexpression of miRNA let-7a or downregulation of elF4E2 did not affect the pattern of global mRNA translation (Fig. 4A). Let-7a overexpression reduced the percentage of fLuc-LRE reporter mRNA in the polysome fractions, which indicates that miRNA-mediated repression targets the translational process (Pillai et al., 2005). Downregulation of eIF4E2 relieved the repression, while the control RL mRNA distribution was not affected (Fig. 4B). Notably, let-7a overexpression reduced the total mRNA level of fLuc-LRE but not the control reporter RL, while downregulation of elF4E2 did not affect the total mRNA level of either reporter (Fig. 4C), indicating that elF4E2 mainly plays a role in the process of miRNA mediated translational repression but not the process of RNA decay.

\section{Downregulation of elF4E2 increases the translational efficiency of endogenous IMP1}

To further demonstrate the role of elF4E2 in miRNA-mediated translational repression, we analyzed the effects of elF4E2 downregulation on the expression of endogenous IMP1 in HeLa cells wherein let-7a is highly expressed. In the 3'UTR of IMP1 coding mRNA, there are six putative let-7 binding sites, which render the mRNA sensitive to the endogenous let-7 (Boyerinas et al., 2008). The IMP1 protein 
A

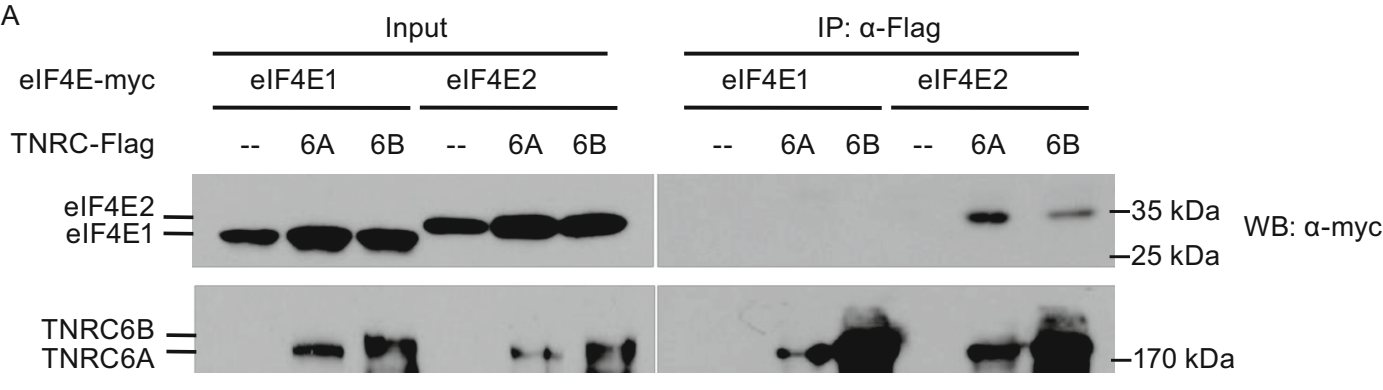

B

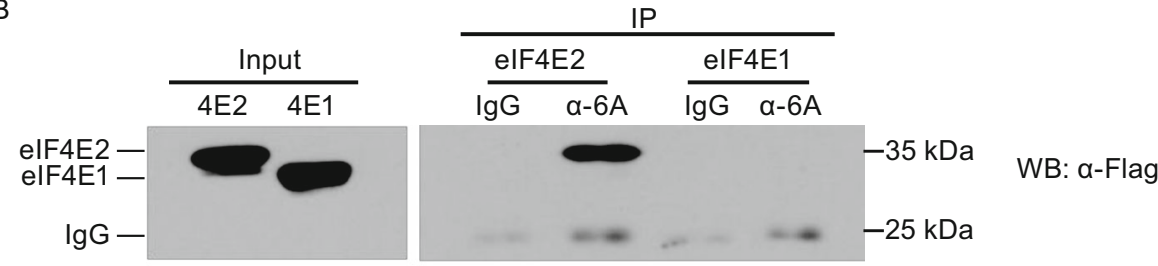

TNRC6A

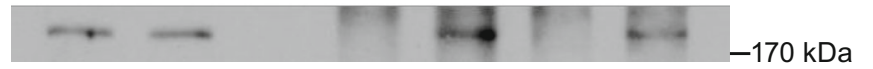

WB: $\alpha-T N R C 6 A$

C
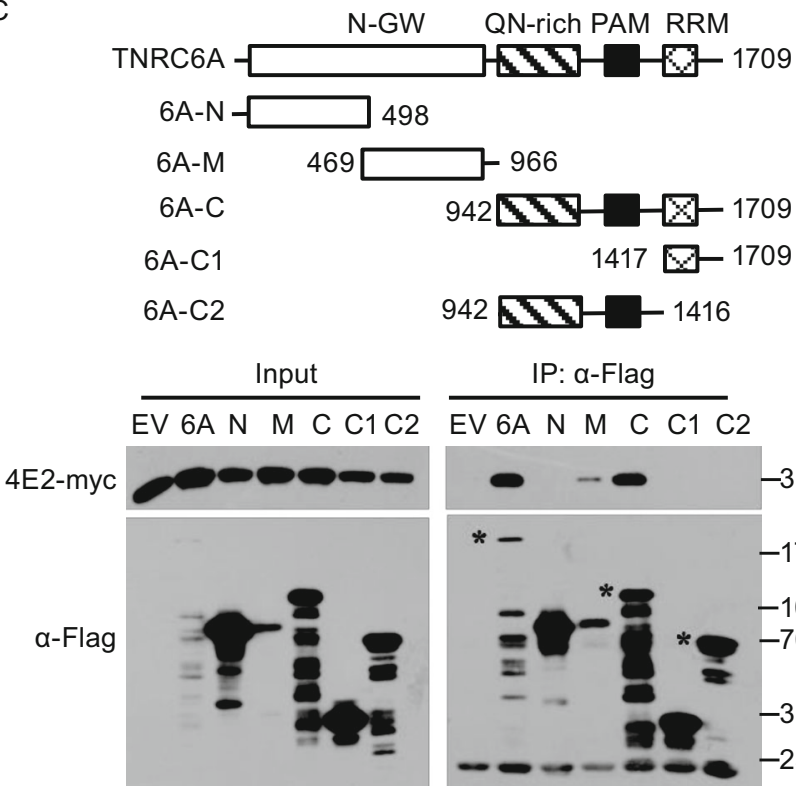

Figure 2. TNRC6A interacts with elF4E2. (A) Plasmids expressing proteins indicated were transfected into HEK293T cells. At $48 \mathrm{~h}$ posttransfection, cells were lysed and the lysates were immunoprecipitated (IP) in the presence of RNase A. The precipitates were resolved on SDS-PAGE followed by Western blotting. (B) A plasmid expressing Flag-tagged elF4E1 or elF4E2 was transfected into HEK293T cells. At $48 \mathrm{~h}$ posttransfection, cells were lysed and the lysates were immunoprecipitated with the anti-TNRC6A antibody or control IgG in the presence of RNase A. The precipitates were resolved on SDS-PAGE followed by Western blotting. (C) Upper: schematic representation of TNRC6A truncation mutants. Lower: A plasmid expressing the TNRC6A mutant indicated and a plasmid expressing myc-tagged eIF4E2 were transiently transfected into HEK293T cells. At $48 \mathrm{~h}$ posttransfection, cells were lysed and the lysates were immunoprecipitated with anti-Flag antibody in the presence of RNase A followed by Western blotting. (D) Bacterially expressed Flag-tagged elF4E2 or elF4E1 was incubated with Glutathione Sepharose 4B bound fusion protein of GST and the C-terminal domain of TNRC6A (6A-C). The precipitates were washed and resolved on SDS-PAGE followed by commassie brilliant blue staining (lower) and Western blotting (upper).

levels were assayed in the absence or presence of the siRNAs targeting elF4E2. Considering that the expression level of TNRC6C is relatively low in HeLa cells compared to
TNRC6A and TNRC6B (Yao et al., 2011), only TNRC6A and TNRC6B were downregulated using a mixture of siRNAs (TNi) targeting each to serve as a positive control. To 
A
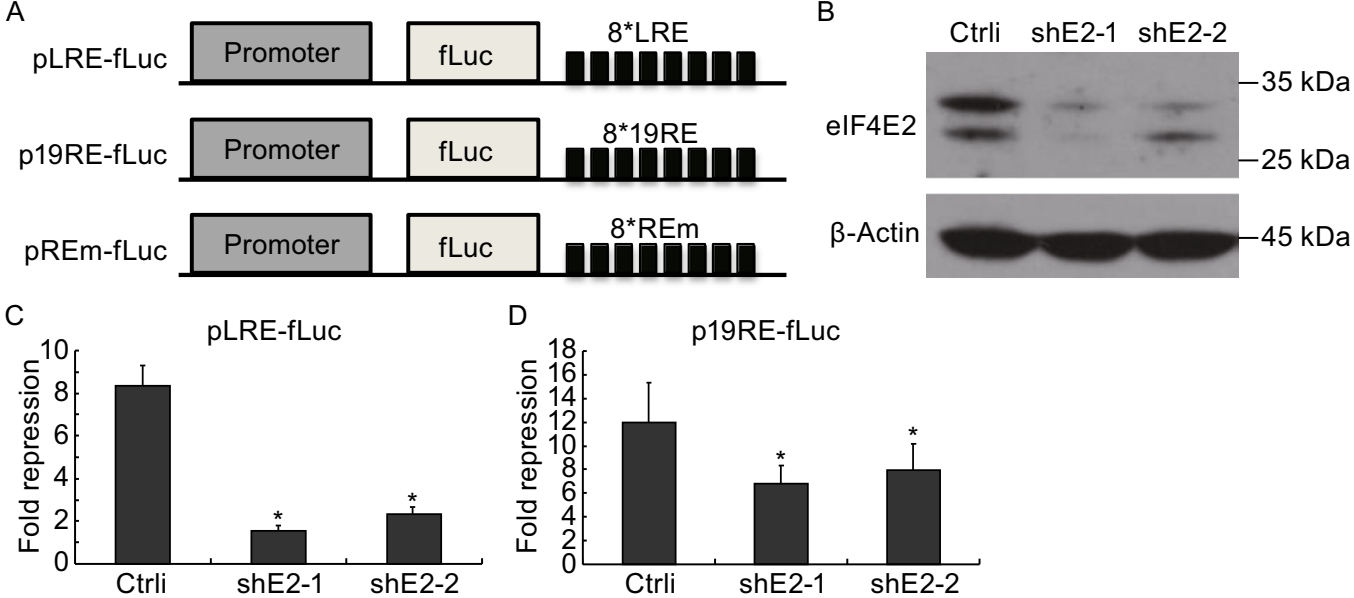

Figure 3. Downregulation of elF4E2 impairs miRNA repression of reporter expression. (A) Schematic representation of reporter plasmids expressing firefly luciferase (fLuc). Eight tandem Let-7a response elements (LRE), miR-19 response elements (19RE), or the mutant response elements (REm) were cloned downstream of the coding sequence of firefly luciferase. (B) Plasmids expressing shRNAs targeting two different sites of elF4E2 (shE2-1 and shE2-2) were individually transfected into HEK293 cells. At $48 \mathrm{~h}$ postinfection, cells were harvested and the lysates were resolved by SDS-PAGE followed by Western blotting. (C) The pLREfLuc reporter and a plasmid expressing a control shRNA or the shRNA targeting elF4E2 were transfected into HEK293 cells with or without a plasmid expressing Let7a. A renilla luciferase-expressing control reporter was included. At $48 \mathrm{~h}$ postinfection, luciferase activities were measured. Firefly luciferase activity was normalized with renilla luciferase activity. Fold repression was calculated as the normalized luciferase activity in the absence of Let7a divided by that in the presence of Let7a. Data presented are means \pm SD of three independent experiments. (D) p19RE-fLuc or pREm-fLuc was transfected into HEK293 cells together with a plasmid expressing a control shRNA or the shRNA targeting elF4E2. A renilla luciferase-expressing reporter was included to serve as a control. At $48 \mathrm{~h}$ postinfection, luciferase activities were measured. Firefly luciferase activity was normalized with renilla luciferase activity. Fold repression was calculated as normalized luciferase activity expressed from pREm-fLuc divided by that expressed from p19RE-fLuc. Data presented are means \pm SD of three independent experiments. The $P$ value is determined by two-tailed Student's $t$ test. ${ }^{*} P<0.05$.

determine whether elF4E2 downregulation had any effect on IMP1 mRNA, the mRNA levels were measured. Relative translational efficiency was calculated as the protein level divided by the mRNA level. Data showed that downregulation of TNRC6A and TNRC6B increased IMP1 protein level by about 3-fold, through increasing both the mRNA level and translational efficiency (Fig. 5A and 5B). Downregulation of elF4E2 with the two siRNAs increased IMP1 protein levels by about 6-fold and 4-fold, respectively, with little effect on the mRNA levels (Fig. 5A and $5 B$ ). In contrast, downregulation of elF4E1 had little effect on either protein or mRNA levels (Fig. 5A and 5B). Noticeably, downregulation of TNRC6A and TNRC6B increased IMP1 protein levels by a lower magnitude compared with elF4E2 (Fig. 5A and 5B). If RISC recruits elF4E2 through TNRC6A to repress translation, one would expect that TNRC6A downregulation should have a more dramatic effect than elF4E2 downregulation. We speculated that this could be accounted for by that the siRNAs targeting TNRC6A and TNRC6B were not as effective as the ones targeting elF4E2 (Fig. 5A). Alternatively, elF4E2 might also work through a yet identified factor to repress translation. In addition to the endogenous IMP1, downregulation of elF4E2 increased the protein levels of endogenous PDCD4 and PTEN (Fig. S2), whose expressions are repressed by endogenous miR-21 (Asangani et al., 2008; Meng et al., 2007; Qi et al., 2009). Collectively, these results indicate that elF4E2 is required for miRNA-mediated translational repression of endogenous proteins.

miRNA silencing enhances elF4E2 association with target mRNA

The affinity of elF4E2 for the cap is about 100 -fold lower than elF4E1 (Zuberek et al., 2007), and the abundance of elF4E2 in mammalian cells is about 10 -fold lower than elF4E1 (Kubacka et al., 2013). However, elF4E2 can be brought to the cap by a transacting factor(s) to increase its local concentrations in the proximity of the cap of target mRNA. Based on the above results, we reasoned that miRNA on a target mRNA would increase elF4E2 binding to the mRNA. To test this hypothesis, we analyzed the association of elF4E2 with reporter mRNAs with or without miRNA silencing. The LRE reporter was transiently expressed in HEK293 cells, together with ectopic expression of let-7a, and Flagtagged elF4E1, and myc-tagged elF4E2. The REm reporter was used as a negative control. Tagged elF4E2 or elF4E1 
A

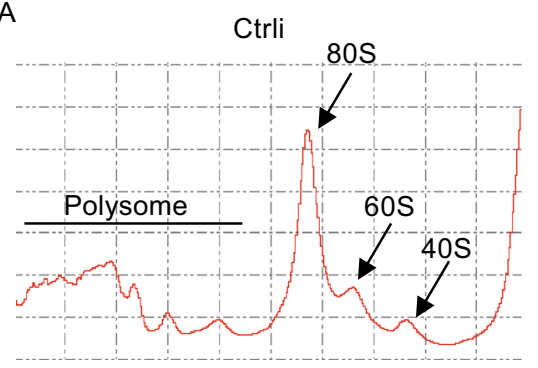

shE2

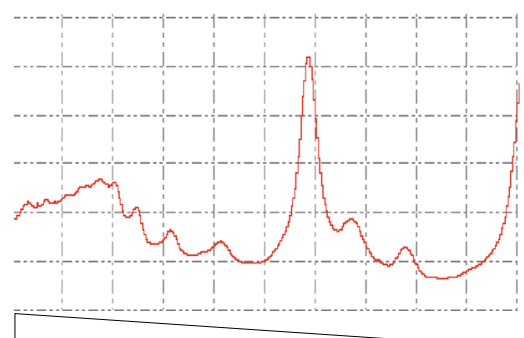

Sucrose gradient

B

fLuc-LRE
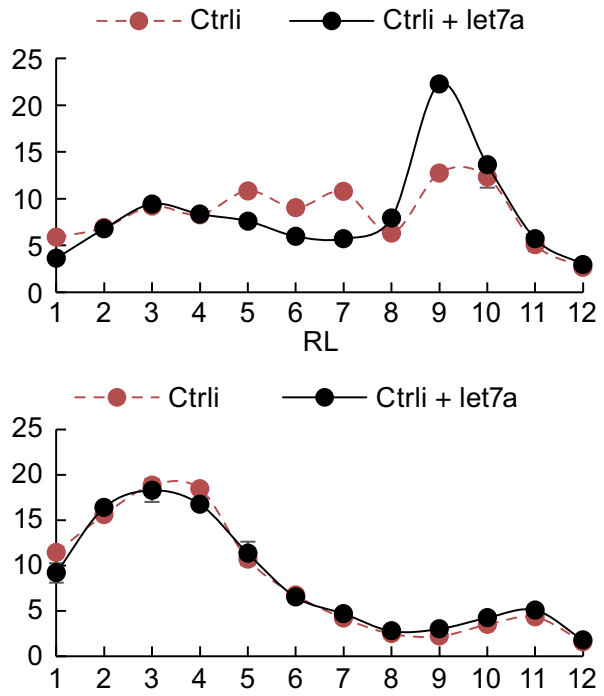

C

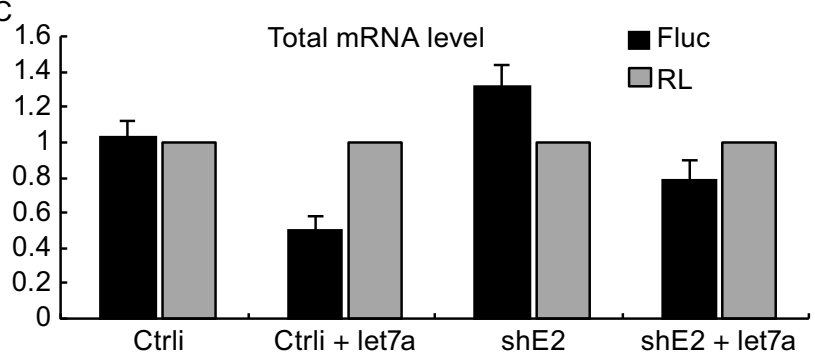

Ctrli + let7a

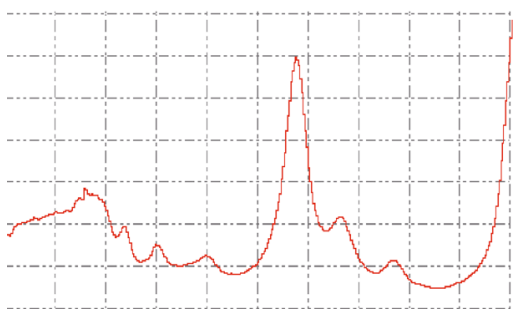

shE2 + let7a

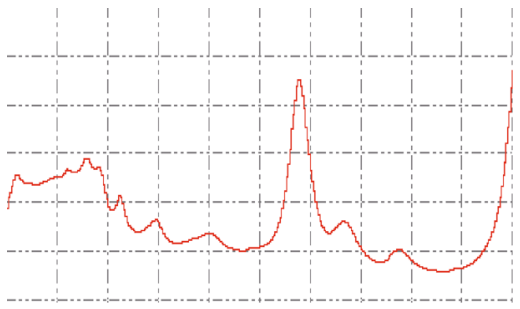

fLuc-LRE

$--\bullet--$ shE2 $\longrightarrow$ shE2 + let7a
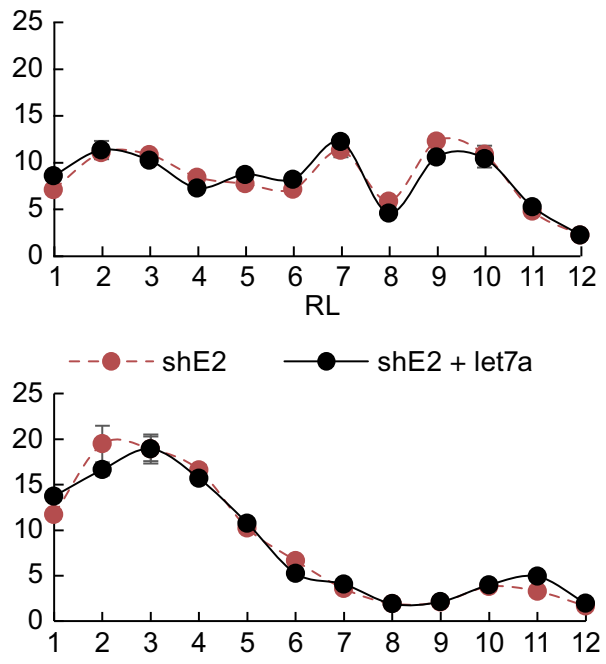

Fluc

shE2 + let7a

Figure 4. Downregulation of elF4E2 relieves miRNA repression of target mRNA translation. (A) A control shRNA (Ctrli) or an shRNA targeting elF4E2 (shE2) were transfected into HEK293 cells with pLRE-fLuc reporter and the control reporter phRL-CMV, together with a plasmid expressing let-7a or a control miRNA. At $48 \mathrm{~h}$ posttransfection, the cells were lysed with RNC buffer containing cycloheximide. The lysate was clarified and separated by velocity sedimentation in a sucrose continuous gradient. Fractions were collected and polysome profile was plotted by 254-nm absorption value. (B) fLuc and RL reporter mRNA levels in each fraction were quantified by RT-qPCR. Y-axis represents the percentage of mRNA in each fraction out of the total mRNA in all the fractions. (C) The total mRNA input before ultra-centrifugation and fractioning. 
A

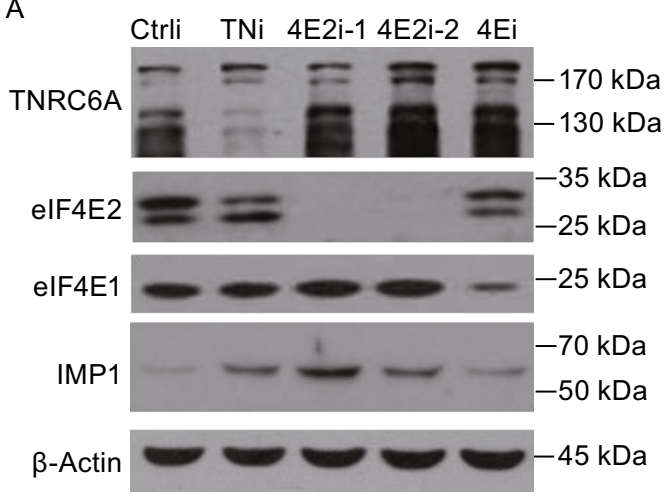

B

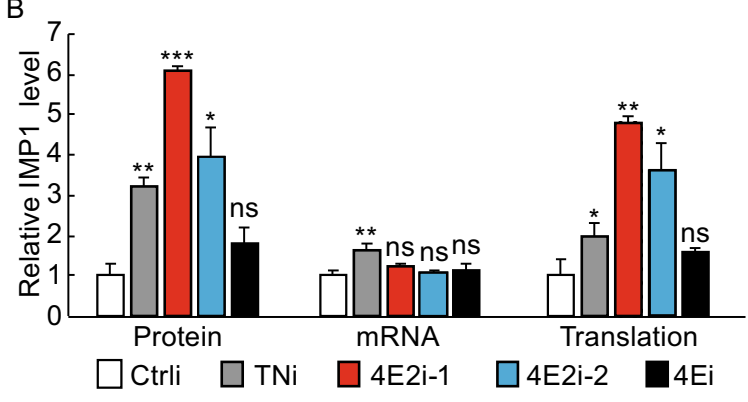

Figure 5. Downregulation of elF4E2 increases the protein levels of endogenous IMP1. HeLa cells were transfected with siRNAs indicated. At $48 \mathrm{~h}$ posttransfection, cells were lysed. (A) A fraction of the lysate was subjected to SDS-PAGE followed by Western blotting. (B) The rest cell lysate was used to extract RNA, followed by RT-qPCR measurement of the RNA levels. Relative IMP1 protein levels were quantified with the Image $\mathrm{J}$ software and normalized with the $\beta$-actin levels. Translational efficiency was calculated as relative protein level divided by mRNA level. Fold repression was calculated as the value in the presence of the control siRNA divided by that in the presence of the targeting siRNA. Data presented are means \pm SD of three independent experiments. The $P$ value is determined by two-tailed Student's $t$ test. ns, nonsignificant. ${ }^{*} P<0.05 ;{ }^{* *} P<0.01 ;{ }^{* \star *} P<0.005$. Ctrli, control siRNA; TNi, siRNAs targeting TNRC6A and TNRC6B; 4E2i, siRNA targeting elF4E2; 4Ei, siRNA targeting elF4E1.

was immunoprecipitated and the amount of associated reporter mRNA was measured. Association of the protein with reporter mRNA was indicated by relative enrichment, which was calculated as the amount of precipitated RNA divided by the amount of the reporter RNA in the input. Data showed that the relative enrichment of elF4E2 for the LRE reporter was about 10 -fold higher than for the REm reporter (Fig. 6A and 6B). In contrast, the relative enrichment of elF4E1 for the LRE reporter was modestly but significantly lower than the REm reporter (Fig. 6A and 6B). These results indicated that miRNA silencing increased the association of the target mRNA with elF4E2 but decreased the association with elF4E1.

These results suggested that miRNA recruited elF4E2 to compete with elF4E1 for binding to the target mRNA. To substantiate this notion, we analyzed whether the cap binding activity of elF4E2 is required for its function in miRNA silencing. The residue W124 of elF4E2 has been reported to be critical for its cap binding activity, and substitution of this residue with alanine (W124A) abolished its cap binding activity (Rom et al., 1998). The endogenous elF4E2 was downregulated in HeLa cells. In the meanwhile, the cells were transfected with a rescue plasmid expressing either the wild-type or the mutant elF4E2, which cannot be targeted by the siRNA. As reported previously, the mutant elF4E2 lost the cap binding activity (Fig. 6C). Downregulation of endogenous elF4E2 in HeLa cells reduced miRNA repression of the LRE-fLuc reporter and ectopic expression of the wild-type elF4E2 restored the repression to some extent (Fig. 6D). In contrast, ectopic expression of the mutant elF4E2-W124A had little effect (Fig. 6D). Downregulation of the endogenous elF4E2 and ectopic expression of the wild-type or mutant elF4E2 were confirmed by Western blotting (Fig. 6E). These results indicated that the cap binding affinity is required for elF4E2 to function in miRNA silencing.

\section{DISCUSSION}

There is increasing evidence indicating that translation initiation is the major target of miRNA repression. It has been recently well established that miRNAs induce the dissociation of elF4A from target mRNA, resulting in the block of the assembly of translational initiation complex (Fukaya et al., 2014; Fukao et al., 2014). However, this is unlikely the only mechanism by which miRNAs repress translation initiation. It has been extensively reported that the $5^{\prime}$ cap of target mRNA is important for miRNA repression (Pillai et al., 2005; Mathonnet et al., 2007; Humphreys et al. 2005; Walters et al., 2010). In this report, we compared the responses to miRNA repression of reporters with or without a structured $5^{\prime}$ UTR. Those with a structured $5^{\prime}$ UTR are presumably affected by elF4A, which is an RNA helicase. We also compared reporters with or without a cap structure. The results collectively confirmed that both the cap and $5^{\prime} \mathrm{UTR}$ are targets of miRNA repression (Fig. 1).

We show that human TNRC6A and 6B, homologues of fly GW182, interacted with elF4E2 (Fig. 2). We proposed that TNRC6 proteins recruited elF4E2 to target mRNA to block translation initiation through competing with elF4E1. This notion was supported by the observation that miRNA repression increased the association of target MRNA with elF4E2 but decreased the association of target mRNA with elF4E1 (Fig. 6). This notion was further supported by the observation that the cap-binding activity of elF4E2 was required for optimal miRNA repression (Fig. 6). In order to 
A

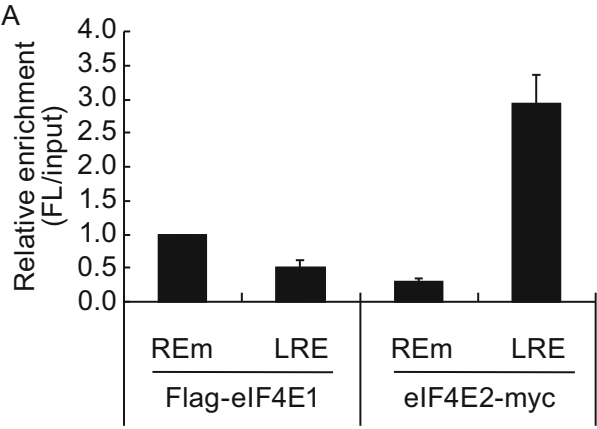

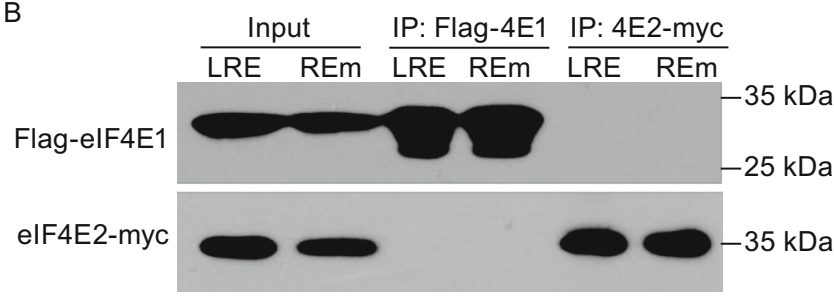

C

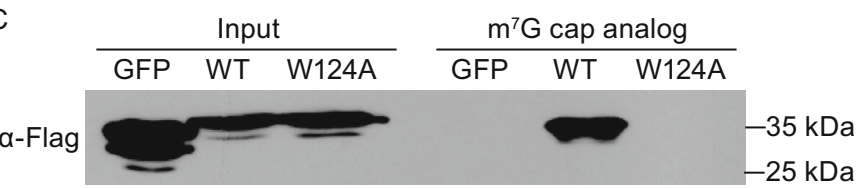

D

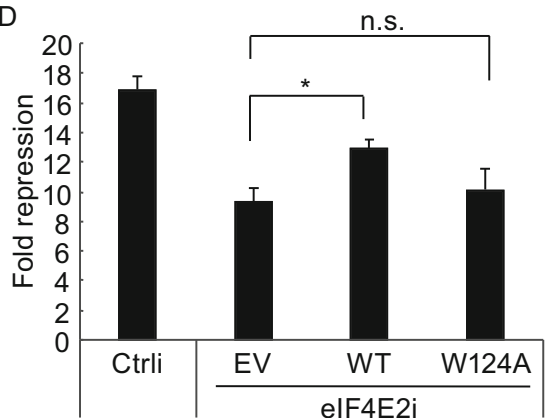

E
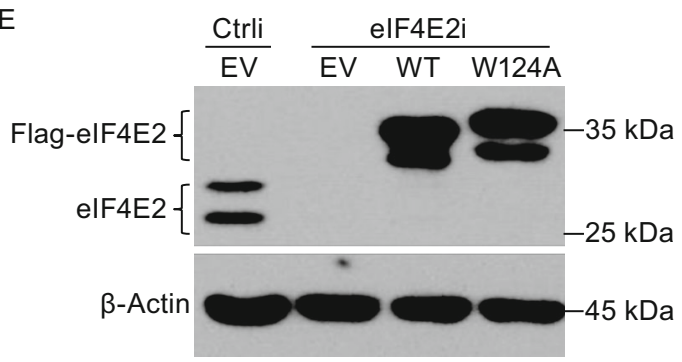

Figure 6. MiRNA silencing increases elF4E2 association with target mRNA. (A and B) HEK293 cells were transfected with plasmids expressing Flag-tagged elF4E1, myc-tagged elF4E2, Let-7a, and reporter pLRE-fLuc or pREm-fLuc. The reporter phRLCMV was included to serve as a control for transfection efficiency and sample handling. At $48 \mathrm{~h}$ postinfection, cells were lysed. (A) The cell lysate was immunoprecipitated with the anti-Flag or anti-myc affinity gel. Reporter mRNA levels were measured by RTqPCR. The fLuc mRNA levels were normalized with the RL mRNA levels. Relative enrichment was calculated as the amount of the reporter mRNA in the precipitates divided by that in the input cell lysate. The relative enrichment of fLuc-REm mRNA by elF4E1 was set as 1. Data presented are means \pm SD of two independent experiments. (B) The cell lysate and the remaining precipitates were resolved on SDS-PAGE followed by Western blotting. (C) Flag-tagged GFP, elF4E2 or its mutant elF4E2-W124A was transiently expressed in HEK293T cells and pulled down with beads conjugated to the cap analog M7-GTP. The cell lysates and precipitates were analyzed by Western blotting. (D and E) HeLa cells were transfected with plasmids expressing the shRNA targeting elF4E2, pLRE-fLuc or pREm-fLuc reporter and a renilla luciferase-expressing control reporter, and a rescue plasmid expressing the wild-type or mutant elF4E2. At $48 \mathrm{~h}$ postinfection, cells were lysed. (D) Luciferase activities were measured. Firefly luciferase activity was normalized with the renilla luciferase activity. Fold repression was calculated as the normalized luciferase activity expressed from pREm-fLuc divided by that from pLRE-fLuc. Data presented are means \pm SD of three independent experiments. The $P$ value is determined by two-tailed Student's $t$ test. ns, nonsignificant. ${ }^{*} P<0.05$. (E) A fraction of the cell lysate was subjected to SDS-PAGE followed by Western blotting.

distinguish elF4E2 contribution to translational repression from mRNA decay in miRNA silencing, we measured reporters' mRNA levels and analyzed the polysome profiling (Fig. 4). The results demonstrate that elF4E2 mainly represses reporter expression on the translational level, without significantly affecting the encoding mRNA levels.

The role of elF4E2 in miRNA repression was demonstrated by the observation that downregulation of elF4E2 reduced miRNA repression of two different reporters (Fig. 3). We further showed that elF4E2 downregulation increased the protein levels of endogenous IMP1, PTEN and PDCD4, whose expression are regulated by endogenous miRNAs including let-7 and miR-21 (Figs. 5 and S2).

During the course of this work, Chapat et al. reported that elF4E2 participates in miRNA repression of target mRNA translation. They showed that miRNA recruited elF4E2 through the CNOT1-RCK-4E-T axis. CNOT1, scaffold subunit of CCR4-NOT, recruits RCK and then 4E-T, which interacts with elF4E2 (Chapat, 2017) (Fig. 7). Here we confirmed their result that elF4E2 is required for miRNA 


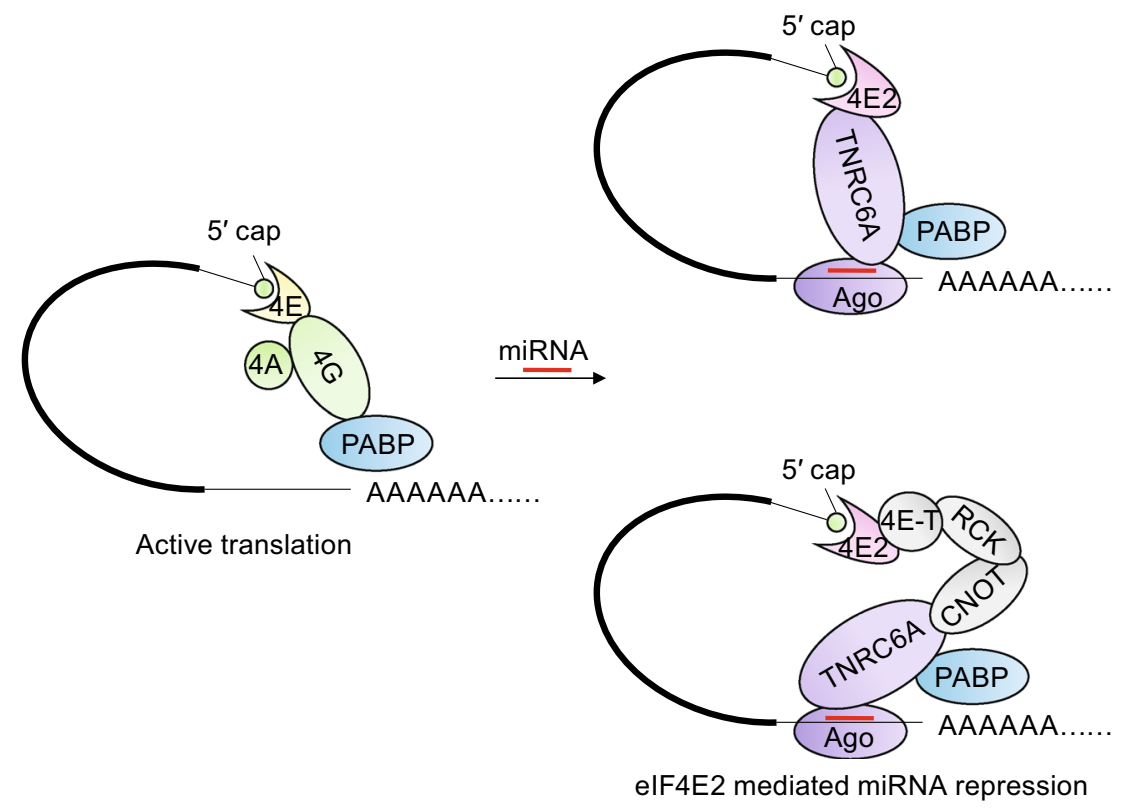

Figure 7. Working models for elF4E2-mediated miRNA repression of target mRNA translation. In the absence of miRNA, target mRNA is translated actively as a $5^{\prime}$ cap-elF4E-elF4G-PABP-3' poly(A) closed loop (left). In the presence of miRNA, RISC is loaded on the target mRNA, and elF4E2 is recruited to the $5^{\prime}$ cap through direct interaction with TNRC6A (upper-right) or through the CNOTRCK-4E-T axis (bottom-right) to compete with elF4E, resulting in translational repression.

repression of target mRNA translation. However, the underlying mechanism reported here is different from theirs. Here we show that elF4E2 is recruited by miRNA through its direct interaction with TNRC6 proteins. Notably, these two mechanisms are complementary to each. Which mechanism plays a major role awaits further investigation.

\section{MATERIALS AND METHODS}

DNA constructs and siRNAs

To generate reporters pLRE-fLuc, p19RE-fLuc and pREm-fLuc, the coding sequence of renilla luciferase of phRL-CMV (Promega) was first replaced with the coding sequence of firefly luciferase (fLuc). The CMV promoter in the vector was replaced with the PGK promoter. An intron sequence of $137 \mathrm{bp}$ was inserted into the $5^{\prime} \mathrm{UTR}$ of the reporters such that DNA contamination was excluded in RTqPCR (Tao and Gao, 2015). Four copies of 2*LRE, 2*19RE or $2^{*} \mathrm{REm}$ were cloned into the $3^{\prime} \mathrm{UTR}$ of the reporters using restriction sites Xbal and Notl. Fragments of 2*LRE, 2*19RE, and ${ }^{*}$ REm were generated by annealing paired oligonucleotides. The sequences of the oligonucleotides are listed in Table S1.

To generate mRNA reporters cap-CAA-fLuc and cap-SL-fLuc, the coding sequence and $3^{\prime} U T R$ of pLRE-fLuc/pREm-fLuc were PCRamplified using forward primers in which the $T 7$ promoter and the 5'UTR (SL or CAA) sequences were built, and cloned into pMD18-T (Takara). The primer sequences are listed in Table S1.

To generate mRNA reporters EMCV-CAA-fLuc, IRES-SL-fLuc and IRES-RL, the EMCV IRES fragment PCR-amplified from pLet7EMCV (Meijer et al., 2013) was first cloned before the coding sequence of pLRE-fLuc/pREm-fLuc/phRL-CMV using restriction sites Sacl and Sacll. CAA or SL sequences were generated by annealing paired oligonucleotides and inserted between the IRES and the firefly luciferase coding sequence using restriction sites Sacll and Ncol. The cassette covering IRES-CAA/SL-fLuc-LRE/ REm was cloned into pBluescript-SK2 (-) (Stratagene) using restriction sites $\mathrm{Xhol}$ and $\mathrm{BamHI}$. Sequences of the primers and oligonucleotides are listed in Table S1.

The shRNAs targeting elF4E2 and a control shRNA have been described previously (Tao and Gao, 2015). To downregulate TNRC6A and TNRC6B, a mixture of siRNAs targeting each of them were used. The sequences of the siRNAs targeting elF4E2, elF4E1, TNRC6A, and TNRC6B are listed in Table S1

\section{In vitro transcription}

To generate mRNA reporters, the plasmids were linearized with $B a m \mathrm{HI}$ followed by chloroform extraction. The mRNAs were generated using the in vitro transcription system (P1300, Promega). Ribo m7G cap analog (P1711, Promega) was added to generate capped RNA transcripts. Then the produced RNA transcripts were added a poly(A) tail using the Poly(A) Tailing Kit (AM1350, Ambion).

Cell culture and transfection

HeLa, HEK293, and HEK293T cells were maintained in Dulbecco's modified Eagle's medium (Invitrogen) supplemented with 10\% fetal bovine serum (Gibco). DNA was transfected using Lipofectamine 2000 (Invitrogen) for HeLa cells and using Neofectin DNA transfection reagent (SciLight) for HEK293 and HEK293T cells. siRNA and mRNA reporters were transfected using Lipofectamine 2000. 


\section{Antibodies}

All the antibodies used in this report were commercially purchased: elF4E1 (Santa Cruz, A-10, sc-271480), elF4E2 (CST, D54C2), TNRC6A (Novus Biologicals, NBP1-28751), $\beta$-actin (GSGB-BIO, TA-09), IMP1 (Santa Cruz, sc-21026), PDCD4 (CST, D29C6), PTEN (Santa Cruz, A2B1, sc-7974), myc-specific mouse monoclonal antibody 9E10 (Santa Cruz Biotechnology, catalogue No. SC-40), Flag-specific mouse monoclonal antibody M2 (Sigma-Aldrich, catalogue No. F3165), Anti-Flag M2 affinity gel (Sigma), Anti-c-Myc Agarose (Sigma), M7-GTP-Sepharose (GE Healthcare Bioscience).

\section{Immunoprecipitation assay}

Cells in a $60-\mathrm{mm}$ dish were lysed in $500 \mu \mathrm{L}$ Co-IP buffer $(30 \mathrm{mmol} / \mathrm{L}$ Hepes, $\mathrm{pH} 7.5,100 \mathrm{mmol} / \mathrm{L} \mathrm{NaCl}, 0.5 \% \mathrm{NP} 40$ ), with protease inhibitor cocktail (Roche) and RNase A (sigma). The lysate was clarified at $12,000 \mathrm{rpm}$ for $10 \mathrm{~min}$ at $4^{\circ} \mathrm{C}$. $50 \mu \mathrm{L}$ cell lysate was solved with SDS loading buffer and used as the input (10\%), and the left was incubated with antibodies and protein $\mathrm{G}$ beads for $2-4 \mathrm{~h}$ at $4^{\circ} \mathrm{C}$. Then the beads were washed 5 times by TBST buffer $(20 \mathrm{mmol} / \mathrm{L}$ Tris- $\mathrm{HCl}, \mathrm{pH} 7.5,500 \mathrm{mmol} / \mathrm{L} \mathrm{NaCl}, 0.1 \%$ Tween 20 ), and analyzed by Western Blotting.

\section{Pull-down assay}

TNRC6A-C and Flag-tagged elF4E/4E2 were cloned into the prokaryotic expression vector pGEX-5x-3-linker (modified from pGEX-5x-3, GE). GST-6A-C and GST-Flag-4E/4E2 were expressed in Escherichia coli (BL21 (DE3), Transgene) and purified following the handbook for the glutathione S-transferase (GST) fusion protein system (Amersham Biosciences). GST was removed using PreScission protease to produce Flag-4E/4E2, which was then incubated with Glutathione Sepharose 4B bound fusion protein of GST and the C-terminal domain of TNRC6A $(6 \mathrm{~A}-\mathrm{C})$. The precipitates were washed by TBST and resolved on SDS-PAGE followed by commassie brilliant blue staining and Western blotting.

\section{RNA extraction and quantitative PCR}

Cytoplasmic RNA was extracted from clarified cell lysate using TRIzol (Invitrogen) following the manufacturer's instructions without DNase treating. RNA concentration was quantified using Nanodrop (Nanodrop Technologies). 1 2 $\mu \mathrm{g}$ RNA was reverse transcribed using random primers (Takara, 3802) and MLV reverse transcriptase. No RT (minus reverse transcriptase) was included as a negative control to exclude the proper effect from plasmids DNA or genomic DNA. Quantitative RT-PCR reactions were performed using specific primers and RealMaster Mix (SYBR Green) (TIANGEN Biotech) in Corbett $6200 / 6600 / 65 \mathrm{HO}$ (Corbett research) with the following cycling condition: $95^{\circ} \mathrm{C}, 10 \mathrm{~min} ; 40 \times\left(95^{\circ} \mathrm{C}, 10 \mathrm{~s} ; 60^{\circ} \mathrm{C}\right.$, $\left.15 \mathrm{~s} ; 72^{\circ} \mathrm{C}, 20 \mathrm{~s}\right)$. The fold change on mRNA levels was calculated relative to the control and normalized to GAPDH mRNA level. Data are means of duplicate measurements by two times of 2 independent experiments. The qPCR primers for pLRE-fLuc, pREm-fLuc, and PhRL-CMV have been described previously (Tao and Gao, 2015). Other primer sequences are listed in Table S1.

\section{Polysome profiling assay}

Cells were lysed with RNC buffer (50 mmol/L Hepes, $\mathrm{pH} 7.4$; $100 \mathrm{mmol} / \mathrm{L} \mathrm{KAc} ; 5 \mathrm{mmol} / \mathrm{L} \mathrm{MgCl}_{2} ; 0.1 \%$ TritonX-100; $1000 \mathrm{U} / \mathrm{mL}$ RNase Inhibitor and $100 \mu \mathrm{g} / \mathrm{mL}$ Cycloheximide were added before using). $0.8 \mathrm{~mL}$ cell lysate supernatant were loaded on $12 \mathrm{~mL}$ $10 \%-50 \%$ sucrose continuous gradient followed by $36,000 \mathrm{rpm}$ ultra-centrifugation for $3 \mathrm{~h}$ and $20 \mathrm{~min}$. Then the samples were through a continuous 254-nm absorbance detector and 12 fractions, $1 \mathrm{~mL}$ each, were collected for each sample. $300 \mu \mathrm{L}$ of each fraction was used for RNA extraction with $1 \mathrm{~mL}$ Trizol and $0.1 \mu \mathrm{g}$ NS1 mRNA as the external reference. The fLuc-LRE and RL mRNA levels were measured by RT-qPCR normalized by NS1 level.

\section{RNA binding assay}

Cells were lysed with cell lysis buffer $(20 \mathrm{mmol} / \mathrm{L} \mathrm{HEPES} \mathrm{KOH}(\mathrm{pH}$ 7.3), $150 \mathrm{mmol} / \mathrm{L} \mathrm{KCl}, 10 \mathrm{mmol} / \mathrm{L} \mathrm{MgCl}_{2}$ and $1 \% \mathrm{NP} 40$ ) (Heiman et al., 2014) supplemented with the protease inhibitor cocktail (Roche), $1 \mathrm{mmol} / \mathrm{L}$ DTT, $1000 \mathrm{U} / \mathrm{mL}$ RNase inhibitor, and $30 \mathrm{mmol} / \mathrm{L}$ $\mathrm{NaBH}_{3} \mathrm{CN}$ (Sonenberg and Shatkin, 1977) for $30 \mathrm{~min}$ on a roller at $4^{\circ} \mathrm{C}$. The lysate was clarified by centrifugation at $12,000 \mathrm{rpm}$ for $15 \mathrm{~min}$ at $4^{\circ} \mathrm{C}$. The clarified lysate was incubated with Anti-c-Myc Agarose (Sigma) and Anti-Flag M2 affinity gel (Sigma) separately for $2 \mathrm{~h}$ on a roller at $4^{\circ} \mathrm{C}$. Immunoprecipitates were washed three times with TBST. Ten percents of the immunoprecipitate was resuspended in SDS loading buffer for protein detection by Western blotting. The remaining immunoprecipitate was resuspended in TRIzol (Invitrogen) for RNA extraction.

\section{ACKNOWLEDGEMENTS}

This work was supported by a grant to Guangxia Gao from Chinese Academy of Sciences under Grant KJZD-EWL10-01.

\section{ABBREVIATIONS}

LREs, Let7a-responsive elements; miRNAs, microRNAs; REm, mutant responsive elements; RISC, RNA-induced silencing complex; RL, renilla luciferase; SL, stem-loop

\section{COMPLIANCE WITH ETHICS GUIDELINES}

The authors declare that they have no conflict of interest. This article does not contain any studies with human or animal subjects performed by any of the authors.

\section{OPEN ACCESS}

This article is distributed under the terms of the Creative Commons Attribution 4.0 International License (http://creativecommons.org/ licenses/by/4.0/), which permits unrestricted use, distribution, and reproduction in any medium, provided you give appropriate credit to the original author(s) and the source, provide a link to the Creative Commons license, and indicate if changes were made. 


\section{REFERENCES}

Asangani IA, Rasheed SA, Nikolova DA, Leupold JH, Colburn NH, Post S, Allgayer H (2008) MicroRNA-21 (miR-21) post-transcriptionally downregulates tumor suppressor $\mathrm{Pdcd} 4$ and stimulates invasion, intravasation and metastasis in colorectal cancer. Oncogene 27(15):2128-2136

Boland A, Tritschler F, Heimstadt S, Izaurralde E, Weichenrieder O (2010) Crystal structure and ligand binding of the MID domain of a eukaryotic Argonaute protein. Embo Reports 11(7):522-527

Boyerinas B, Park SM, Shomron N, Hedegaard MM, Vinther J, Andersen JS, Feig C, Xu J, Burge CB, Peter ME (2008) Identification of let-7-regulated oncofetal genes. Cancer Res 68 (8):2587-2591

Chapat C, Jafarnejad SM, Matta-Camacho E, Hesketh GG, Gelbart IA, Attig J, Gkogkas CG, Alain T, Stern-Ginossar N, Fabian MR et al (2017) Cap-binding protein 4EHP effects translation silencing by microRNAs. Proc Natl Acad Sci 114:5425-5430

Cho PF, Poulin F, Cho-Park YA, Cho-Park IB, Chicoine JD, Lasko P, Sonenberg $N$ (2005) A new paradigm for translational control: inhibition via 5 ' -3 ' mRNA tethering by Bicoid and the elF4E cognate 4EHP. Cell 121(3):411-423

Djuranovic S, Zinchenko MK, Hur JK, Nahvi A, Brunelle JL, Rogers EJ, Green R (2010) Allosteric regulation of Argonaute proteins by miRNAs. Nat Struct Mol Biol 17(2):144-150

Eulalio A, Huntzinger E, Izaurralde E (2008) GW182 interaction with Argonaute is essential for miRNA-mediated translational repression and mRNA decay. Nat Struct Mol Biol 15(4):346-353

Fabian MR, Sonenberg N, Filipowicz W (2010) Regulation of mRNA translation and stability by microRNAs. Annu Rev Biochem 79:351-379

Flynt AS, Lai EC (2008) Biological principles of microRNA-mediated regulation: shared themes amid diversity. Nat Rev Genet 9 (11):831-842

Frank F, Fabian MR, Stepinski J, Jemielity J, Darzynkiewicz E, Sonenberg N, Nagar B (2011) Structural analysis of 5 '-mRNAcap interactions with the human AGO2 MID domain. Embo Reports 12(5):415-420

Fu R, Olsen MT, Webb K, Bennett EJ, Lykke-Andersen J (2016) Recruitment of the 4EHP-GYF2 cap-binding complex to tetraproline motifs of tristetraprolin promotes repression and degradation of mRNAs with AU-rich elements. RNA 22(3):373-382

Fukao A, Mishima Y, Takizawa N, Oka S, Imataka H, Pelletier J, Sonenberg N, Thoma C, Fujiwara T (2014) MicroRNAs trigger dissociation of elF4AI and elF4All from target mRNAs in humans. Mol Cell 56(1):79-89

Fukaya T, Tomari Y (2012) MicroRNAs mediate gene silencing via multiple different pathways in drosophila. Mol Cell 48(6):825-836

Fukaya T, Iwakawa HO, Tomari Y (2014) MicroRNAs block assembly of elF4F translation initiation complex in Drosophila. Mol Cell 56(1):67-78

Gingras AC, Raught B, Sonenberg N (1999) elF4 initiation factors: effectors of mRNA recruitment to ribosomes and regulators of translation. Annu Rev Biochem 68:913-963

Gu W, Xu Y, Xie X, Wang T, Ko JH, Zhou T (2014) The role of RNA structure at 5' untranslated region in microRNA-mediated gene regulation. RNA 20(9):1369-1375
Heiman M, Kulicke R, Fenster RJ, Greengard P, Heintz N (2014) Cell type-specific mRNA purification by translating ribosome affinity purification (TRAP). Nat Protoc 9(6):1282-1291

Humphreys DT, Westman BJ, Martin DI, Preiss T (2005) MicroRNAs control translation initiation by inhibiting eukaryotic initiation factor 4E/cap and poly(A) tail function. Proc Natl Acad Sci U S A 102 (47):16961-16966

Jackson RJ, Hellen CU, Pestova TV (2010) The mechanism of eukaryotic translation initiation and principles of its regulation. Nat Rev Mol Cell Biol 11(2):113-127

Jonas S, Izaurralde E (2015) NON-CODING RNA Towards a molecular understanding of microRNA-mediated gene silencing. Nat Rev Genet 16(7):421-433

Kamenska A, Lu WT, Kubacka D, Broomhead H, Minshall N, Bushell M, Standart N (2014) Human 4E-T represses translation of bound mRNAs and enhances microRNA-mediated silencing. Nucleic Acids Res 42(5):3298-3313

Kamenska A, Simpson C, Vindry C, Broomhead H, Benard M, Ernoult-Lange M, Lee BP, Harries LW, Weil D, Standart N (2016) The DDX6-4E-T interaction mediates translational repression and P-body assembly. Nucleic Acids Res 44(13):6318-6334

Kinch LN, Grishin NV (2009) The human Ago2 MC region does not contain an elF4E-like mRNA cap binding motif. Biol Direct 4:2

Kiriakidou M, Tan GS, Lamprinaki S, De Planell-Saguer M, Nelson PT, Mourelatos Z (2007) An mRNA m(7)G cap binding-like motif within human Ago2 represses translation. Cell 129 (6):1141-1151

Kubacka D, Kamenska A, Broomhead H, Minshall N, Darzynkiewicz E, Standart N (2013) Investigating the consequences of elF4E2 (4EHP) interaction with 4E-transporter on its cellular distribution in HeLa cells. PLoS ONE 8(8):e72761

Lu WT, Wilczynska A, Smith E, Bushell M (2014) The diverse roles of the elF4A family: you are the company you keep. Biochem Soc Trans 42:166-172

Mathonnet G, Fabian MR, Svitkin YV, Parsyan A, Huck L, Murata T, Biffo S, Merrick WC, Darzynkiewicz E, Pillai RS et al (2007) MicroRNA inhibition of translation initiation in vitro by targeting the cap-binding complex elF4F. Science 317(5845):17641767

Meijer HA, Kong YW, Lu WT, Wilczynska A, Spriggs RV, Robinson SW, Godfrey JD, Willis AE, Bushell M (2013) Translational repression and elF4A2 activity are critical for microRNA-mediated gene regulation. Science 340(6128):82-85

Meister G (2007) miRNAs get an early start on translational silencing. Cell 131(1):25-28

Meng FY, Henson R, Wehbe-Janek H, Ghoshal K, Jacob ST, Patel T (2007) MicroRNA-21 regulates expression of the PTEN tumor suppressor gene in human hepatocellular cancer. Gastroenterology 133(2):647-658

Nishimura T, Padamsi Z, Fakim H, Milette S, Dunham WH, Gingras AC, Fabian MR (2015) The elF4E-Binding Protein 4E$\mathrm{T}$ Is a Component of the mRNA Decay Machinery that Bridges the 5 ' and 3 ' Termini of Target mRNAs. Cell Rep 11(9):14251436

Petersen CP, Bordeleau ME, Pelletier J, Sharp PA (2006) Short RNAs repress translation after initiation in mammalian cells. Mol Cell 21(4):533-542 
Pfaff J, Meister G (2013) Argonaute and GW182 proteins: an effective alliance in gene silencing. Biochem Soc Trans 41 (4):855-860

Pillai RS, Bhattacharyya SN, Artus CG, Zoller T, Cougot N, Basyuk E, Bertrand E, Filipowicz W (2005) Inhibition of translational initiation by Let-7 microRNA in human cells. Science 309 (5740):1573-1576

Qi L, Bart J, Tan LP, Platteel I, Sluis T, Huitema S, Harms G, Fu L, Hollema H, Berg A (2009) Expression of miR-21 and its targets (PTEN, PDCD4, TM1) in flat epithelial atypia of the breast in relation to ductal carcinoma in situ and invasive carcinoma. BMC Cancer 9:163

Ricci EP, Limousin T, Soto-Rifo R, Rubilar PS, Decimo D, Ohlmann T (2013) miRNA repression of translation in vitro takes place during 43S ribosomal scanning. Nucleic Acids Res 41(1):586-598

Rom E, Kim HC, Gingras AC, Marcotrigiano J, Favre D, Olsen H, Burley SK, Sonenberg N (1998) Cloning and characterization of 4EHP, a novel mammalian elF4E-related cap-binding protein. J Biol Chem 273(21):13104-13109

Sonenberg N, Shatkin AJ (1977) Reovirus messenger-Rna can be covalently crosslinked via 5' cap to proteins in initiation-complexes. Proc Natl Acad Sci USA 74(10):4288-4292
Tao X, Gao G (2015) Tristetraprolin Recruits Eukaryotic Initiation Factor 4E2 To Repress Translation of AU-Rich Element-Containing mRNAs. Mol Cell Biol 35(22):3921-3932

Thermann R, Hentze MW (2007) Drosophila miR2 induces pseudopolysomes and inhibits translation initiation. Nature 447 (7146):875-878

Valencia-Sanchez MA, Liu J, Hannon GJ, Parker R (2006) Control of translation and mRNA degradation by miRNAs and siRNAs. Genes Dev 20(5):515-524

Varani G (1997) A cap for all occasions. Structure 5(7):855-858

Walters RW, Bradrick SS, Gromeier M (2010) Poly(A)-binding protein modulates mRNA susceptibility to cap-dependent miRNA-mediated repression. Rna 16(1):239-250

Wang BB, Yanaz A, Novina CD (2008) MicroRNA-repressed mRNAs contain $40 \mathrm{~S}$ but not $60 \mathrm{~S}$ components. Proc NatL Acad Sci USA 105(14):5343-5348

Yao B, Li SQ, Jung HM, Lian SL, Abadal GX, Han F, Fritzler MJ, Chan EKL (2011) Divergent GW182 functional domains in the regulation of translational silencing. Nucleic Acids Res 39(7):2534-2547

Zuberek J, Kubacka D, Jablonowska A, Jemielity J, Stepinski J, Sonenberg N, Darzynkiewicz E (2007) Weak binding affinity of human 4EHP for mRNA cap analogs. RNA 13(5):691-697 